\title{
Determination of application parameters for cotton defoliants in the Yellow River Basin
}

\author{
Xin $\mathrm{Han}^{2}$, J inyou Yu², Yubin Lan ${ }^{1,2^{*}}$, Fanxia Kong², Lili Yi \\ (1. National Sub-center for International Collaboration Research on Precision Agricultural Aviation Pesticide Spraying Technology, Zibo, \\ 255000, China; 2. College of Agricultural Engineering and Food Science, Shandong University of Technology, Zibo, 255000, China)
}

\begin{abstract}
The differences in the growing conditions and the cotton varieties used in the cotton-growing areas in Xinjiang and the Yellow River Basin result in different operating parameters required for unmanned aerial vehicle (UAV)-based plant spraying operations in the two regions. In this experiment, a multi-rotor plant protection drone was used for the application of cotton defoliant in the Yellow River Basin to determine the optimum dosages of the defoliant ethepon. The experiment consisted of six treatments; $40 \mathrm{~g}$ of thidiazuron, $1 \mathrm{~mL}$ of an additive, and different amounts of ethephon (50, 70, 90, 110, and $130 \mathrm{~mL}$ ) were applied. The defoliation rate was measured on the 5, 10, 15, and 20 days after the chemical application and the correlation between the ethepon concentration and the defoliation rate as well as the cotton boll opening rate was determined. The results showed that the application of $90 \mathrm{~mL}$ ethephon resulted in the optimal defoliation effect and ripening of the cotton on 5 and 15 days respectively after the chemical application. It was found that the ethephon application had a larger effect on the cotton defoliation than the ripening rate. The results of this study provide reference data for the use of a plant protection drone for applying cotton defoliants in the Yellow River Basin.
\end{abstract}

Keywords: drone, UAV, cotton defoliant, ethephon, defoliation rate, Shandong

DOI: 10.33440/j.ijpaa.20190201.0016

Citation: Han X, Yu J Y, Lan Y B, Kong F X, Yi L L. Determination of application parameters for cotton defoliants in the Yellow River Basin. Int J Precis Agric Aviat, 2019; 2(1): 51-55.

\section{Introduction}

The Cotton is an important commodity and staple agricultural product related to the national economy and people's livelihood. It is one of the three major raw materials of important cash crops and textile industry in China ${ }^{[1-4]}$. Shandong province is located in the Yellow River basin of China's three major cotton producing areas (The Yangtze river basin, The Yellow River basin and Xinjiang), belongs to the warm temperate zone monsoon climate, There are 180-200 frost-free days and 2500-2800 hours of light per year; Autumn day high air, which is beneficial to the bolls mature boll opening, cotton production has the advantageous conditions for development ${ }^{[5-8]}$. However, due to the irregular land in Shandong, the cotton fields are scattered and the general planting area is small. Therefore, the cotton industry in Shandong Province is less mechanized than the other two cotton areas ${ }^{[9-11]}$. In recent years, the use of UAVs has resulted in the development of a set of empirical parameters for cotton varieties and planting methods in the Xinjiang cotton-growing area and comparisons were conducted of the cotton varieties and the geographical environment in Shandong and Xinjiang. The difference between the cotton varieties results in large differences in plant characteristics and leaf growth position between the of Shandong and Xinjiang cotton. In

\section{Received date: 2019-10-10 Accepted date: 2019-10-20}

Biographies: Xin Han, PhD, Associate Professor, research interests: Precision agricultural aviation, Email: hanxin@sdut.edu.cn; Jinyou Yu, Postgraduate student, research interests: Precision agricultural aviation, Email: 1305899755@ qq.com; Fanxia Kong, PhD, Lecturer, research interests: Precision agricultural aviation, Email: kfx0309@163.com; Lili Yi, PhD, Lecturer, research interests: Precision agricultural aviation, Email: yili0001@sdut.edu.cn.

*Corresponding author: Yubin Lan, PhD, Distinguished Professor, Dean of College of Agricultural Engineering and Food Science, Shandong University of Technology, P. R. China, research interests: Precision agricultural aviation. Email: ylan@sdut.edu.cn. the Shandong cotton, the branches are longer and cross each other, which is lush growth than the cotton grown in Xinjiang and other areas. This has resulted in a lack of plant protection in Xinjiang. The flight parameters of the UAV are not applicable to the Shandong cotton ${ }^{[12-16]}$. Moreover, in Shandong, cotton farmers are not very satisfied with the defoliant application by drones. Most farmers still use human machinery or ground machinery for defoliation; therefore, most of the drone operating parameters are in the exploratory stage $\mathrm{e}^{[15-17]}$. In this study, we conduct experiments to determine the optimum application ratio of cotton defoliants for drone-based spraying of Shandong cotton varieties. The objectives are to improve the ripening and defoliation of cotton for earlier harvesting in Shandong, improve the efficiency of cotton harvesting, and the grade of the cotton ${ }^{[17-25]}$.

\section{Materials and methods}

\subsection{Laboratory equipment}

The plant protection drone used in the test is a Guangzhou Pfeiffer P30 2018 quadrotor plant protection drone equipped with GPS navigation; the body size is $1945 \times 1945 \times 440$ (mm) and the sprayer has four centrifugal nozzles that produce particle atomization of 85-295 micron. The drone system is equipped with route planning and is suitable for continuous spraying and other functions.

The tested defoliation agent consisted of $50 \%$ of thidiazuron as a water-soluble powder, ethephon, and special additives provided by the Anyang Quanfeng agricultural aviation company.

\subsection{Overview of the test site}

The test site is located at the experimental base of the Lufeng Company in Wudi County, Binzhou. The site is also the Ministry of Agriculture and Rural Areas core demonstration area for mechanization technology for cotton production. The area covers more than 2,000 acres. The soil texture of the test site is saline-alkali land. The planting type of "a mulch has three rows" 
is used and the row spacing of the cotton plants is $76 \mathrm{~cm}$.

The test was carried out on Tuesday, 25 May 2018 at 10:00 am; the weather was clear with no wind and the air temperature was $25.3^{\circ} \mathrm{C}$.

\subsection{Test varieties}

The cotton variety tested was Yufeng 103 (Figure 1).

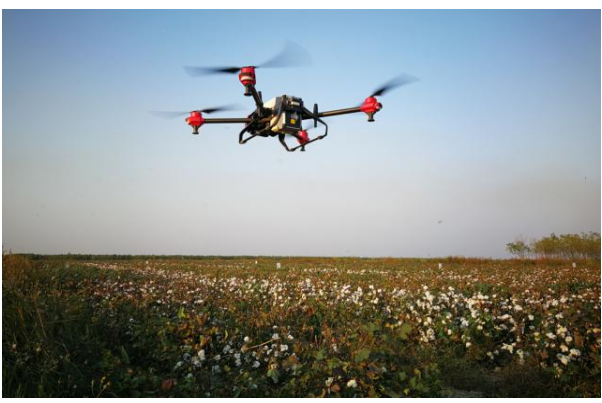

Figure 1 Drone flying over the experimental cotton site

\subsection{Experimental design}

The experiment consisted of six treatments (Table 1); each treatment area covered 1 acre and all areas were sprayed by drones. The dosage of $50 \%$ thidiazuron was $40 \mathrm{~g}$ and the same for treatments 1-5 treatments. The ethephon dosages for the 5 treatments were 50,70,90,110, and $130 \mathrm{~mL}$ and treatment 6 was the control group with water.

Table 1 Experimental plan processing design

\begin{tabular}{|c|c|c|c|}
\hline Treatment & Area $/ \mathrm{m}^{2}$ & $667 \mathrm{~m}^{2}$ Dosage & $\begin{array}{l}667 \mathrm{~m}^{2} \text { water } \\
\text { consumption } / \mathrm{kg}\end{array}$ \\
\hline 1 & 667 & $\begin{array}{l}\text { thidiazuron } 40 \mathrm{~g}+\text { ethephon } 50 \mathrm{~mL}+ \\
\text { additive } 1 \mathrm{~mL}\end{array}$ & 0.8 \\
\hline 2 & 667 & $\begin{array}{l}\text { thidiazuron } 40 \mathrm{~g}+\text { ethephon } 70 \mathrm{~mL}+ \\
\text { additive } 1 \mathrm{~mL}\end{array}$ & 0.8 \\
\hline 3 & 667 & $\begin{array}{l}\text { thidiazuron } 40 \mathrm{~g}+\text { ethephon } 90 \mathrm{~mL}+ \\
\text { additive } 1 \mathrm{~mL}\end{array}$ & 0.8 \\
\hline 4 & 667 & $\begin{array}{l}\text { thidiazuron } 40 \mathrm{~g}+\text { ethephon } 110 \mathrm{~mL} \\
\text { + additive } 1 \mathrm{~mL}\end{array}$ & 0.8 \\
\hline 5 & 667 & $\begin{array}{l}\text { thidiazuron } 40 \mathrm{~g} \text { + ethephon } 130 \mathrm{~mL} \\
\text { + additive } 1 \mathrm{~mL}\end{array}$ & 0.8 \\
\hline $6(\mathrm{CK})$ & 667 & water & 0.8 \\
\hline
\end{tabular}

\subsection{Dispensing method}

Because ethephon is strongly acidic and thidiazuron is weakly alkaline, the pesticides were dispensed using the repeat the method of dilution twice:

1) First, a sufficient amount of water was added to the vat;

2) The thidiazuron and ethephon were diluted separately using a small barrel:

3) The diluted thidiazuron and ethephon were mixed in a large bucket;

4) The additive was added, the mixture was stirred, and water was added to the required amount.

\subsection{Experimental investigation}

Three points were randomly selected in each treatment area and 10 representative cotton plants were selected for labeling at each point as a survey point. The sample points did not include seedlings and double plants were not counted. The growth of the cotton plants at the survey points was consistent.

During the test period, four investigations were conducted. Prior to the application, the total number of leaves, the total number of bolls, and the number of bolls of each cotton plant were determined. When the base of the plants was investigated prior to the experiment, the new small leaves of the cotton plants (leaf width less than $1 \mathrm{~cm}$ ) were not counted. The number of leaves and the number of bolls were measured at $5,10,15$, and $20 \mathrm{~d}$ after application and the defoliation rate and the boll opening rate of each treatment were calculated.

The effect of medicament on cotton defoliation:

$$
\text { Defoliation rate }(\%)=\frac{A-B}{A} \times 100 \%
$$

where, $A=$ Total number of cotton leaves before application; $B=$ Number of leaves remaining on cotton plants at the time of investigation.

$$
\text { Defoliation effect }(\%)=\frac{C-D}{1-D} \times 100 \%
$$

where, $C=$ Treatment area leaf drop rate; $D=$ Control area leaf drop rate.

The medicament promote the effect of the cotton boll opening:

$$
\text { Cotton boll rate(\%) }=\frac{E}{F} \times 100 \%
$$

where, $E=$ The number of cotton bolls; $F=$ The total number of bolls.

$$
\text { Ripening effect }(\%)=\frac{G-F}{1-F} \times 100 \%
$$

where, $G=$ Treatment area cotton boll rate; $H=$ Control boll rate.

SPSS software was used for the statistical analysis to conduct multiple comparisons of the ripening effect and defoliation effect between the treatments ${ }^{[26]}$.

\section{Results and analysis}

\subsection{Defoliation rate and defoliation effect of the different treatments for the same spraying conditions}

Table 2 shows that $5 \mathrm{~d}$ after the application, the defoliation rate did not differ much between the 5 treatments and the control group. However, there are large differences between the treatments. It is assumed that the defoliation agent did not have an effect at five days after application. Ten days after the application, the defoliation rate of the cotton was in the range of $30 \%-50 \%$; the defoliation rate was $60 \%-70 \%$ after $15 \mathrm{~d}$ and $70 \%$ to nearly $90 \%$ after $20 \mathrm{~d}$. A rapid change in the rate of defoliation occurs between 10 and $15 \mathrm{~d}$ after application. Moreover, the defoliation

\begin{tabular}{|c|c|c|c|c|c|c|c|c|c|}
\hline \multirow{2}{*}{ Treatment } & \multirow{2}{*}{$\begin{array}{c}\text { Total number of } \\
\text { blades }\end{array}$} & \multicolumn{2}{|c|}{5 days after application } & \multicolumn{2}{|c|}{10 days after application } & \multicolumn{2}{|c|}{15 days after application } & \multicolumn{2}{|c|}{20 days after application } \\
\hline & & $\begin{array}{l}\text { Number of } \\
\text { blades }\end{array}$ & $\begin{array}{l}\text { Defoliation } \\
\text { rate }\end{array}$ & $\begin{array}{c}\text { Number of } \\
\text { blades }\end{array}$ & $\begin{array}{l}\text { Defoliation } \\
\text { rate }\end{array}$ & $\begin{array}{l}\text { Number of } \\
\text { blades }\end{array}$ & $\begin{array}{l}\text { Defoliation } \\
\text { rate }\end{array}$ & $\begin{array}{c}\text { Number of } \\
\text { blades }\end{array}$ & $\begin{array}{l}\text { Defoliation } \\
\text { rate }\end{array}$ \\
\hline 2 & 1866 & 1536 & $17.68 \%$ & 1278 & $31.50 \%$ & 665 & $64.30 \%$ & 611 & $67.20 \%$ \\
\hline 3 & 1837 & 1487 & $19.00 \%$ & 887 & $51.70 \%$ & 501 & $72.70 \%$ & 233 & $87.30 \%$ \\
\hline 4 & 1664 & 1392 & $16.30 \%$ & 1040 & $37.50 \%$ & 518 & $68.80 \%$ & 373 & $77.23 \%$ \\
\hline 5 & 1898 & 1503 & $17.28 \%$ & 1166 & $38.56 \%$ & 670 & $64.69 \%$ & 537 & $71.70 \%$ \\
\hline CK & 1363 & 1237 & $9.24 \%$ & 994 & $27.07 \%$ & 898 & $34.11 \%$ & 855 & $37.20 \%$ \\
\hline
\end{tabular}
rate of treatment 3 was significantly higher than that of the other treatments at different times.

Table 2 Defoliation rate of cotton for different treatments 
Figure 2 shows the Histogram of defoliation rate of cotton under different treatments, from which it can be more intuitive to see the variation differences among different treatments. In treatment 3 , the peak value and growth trend of defoliation rates of cotton are obviously better than other treatments.

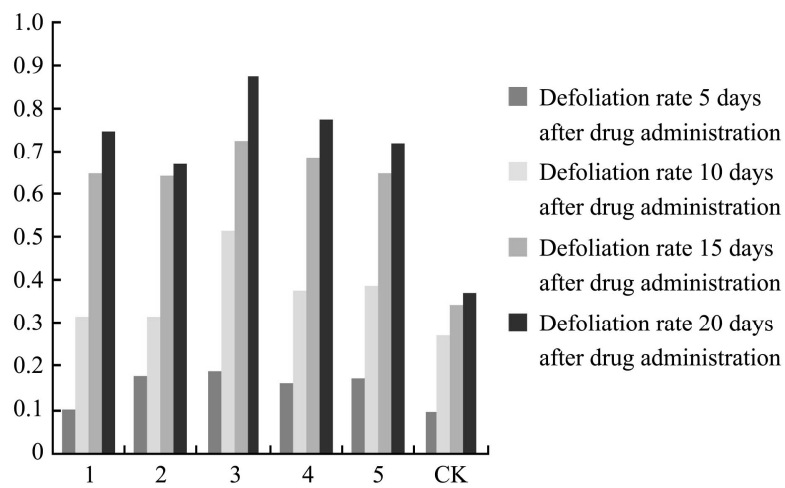

Figure 2 Cotton defoliation rate under different treatments

Table 3 shows a marked change in the defoliation effect $10 \mathrm{~d}$ after application; treatment 3 results in a significantly larger defoliation effect than the other treatments. The defoliation effect $5 \mathrm{~d}$ after application in treatment 1 drug was 0.837 , i.e., the defoliation effect was very small compared to the control group. In addition, there is only a difference of $0.76 \%$ between treatment 1 and the control group.

Table 3 Defoliation of cotton for different treatments

\begin{tabular}{ccccc}
\hline Treatment & $\begin{array}{c}\text { Defoliation } \\
\text { effect 5 days } \\
\text { after } \\
\text { application }\end{array}$ & $\begin{array}{c}\text { Defoliation } \\
\text { effect 10 days } \\
\text { after } \\
\text { application }\end{array}$ & $\begin{array}{c}\text { Defoliation } \\
\text { effect 15 days } \\
\text { after } \\
\text { application }\end{array}$ & $\begin{array}{c}\text { Defoliation } \\
\text { effect 20 days } \\
\text { after } \\
\text { application }\end{array}$ \\
\hline 1 & 0.837 & 6.074 & 46.122 & 59.713 \\
2 & 9.299 & 6.074 & 45.819 & 47.771 \\
3 & 10.754 & 33.772 & 58.567 & 79.777 \\
4 & 7.779 & 14.301 & 52.648 & 63.742 \\
5 & 8.859 & 15.755 & 46.411 & 54.936 \\
\hline
\end{tabular}

3.2 Ripening effect of the cotton for different spraying conditions

As it was shown in Figure 2, the acquired ratio of lignans was increased slightly with increasing of the extraction temperature. This observation suggests that the extraction temperature had no significant effect on the acquired ratio of lignans.

The extraction of lignans was increased slightly with increasing of the extraction temperature by enhancing the solubility of lignans in solvent. But very high extraction temperatures will decrease the activity of lignans and increase the consumption of solvent sharply, because the boiling point of ethanol is as low as $78.3^{\circ} \mathrm{C}$. Manipulation steps and extraction costs are expected to increase with increasing of the extraction temperature. Thus, the extraction temperatures ranging from $20^{\circ} \mathrm{C}$ to $40^{\circ} \mathrm{C}$ were selected as the extraction temperatures for the optimization design. Experiments for selecting the optimal extraction time were conducted at room temperature.

\subsection{Influence of extraction time course on acquired ratio of lignans}

It can be seen from Table 4 that the trend of the cotton boll opening rate was almost the same as that of the cotton defoliation rate. However, the stage when a marked change occurred in the boll opening rate was at $10 \mathrm{~d}$ after application and was in the range of $50 \%-60 \%$; the boll opening rate was $60 \%$ or higher at $15 \mathrm{~d}$ after application. At $20 \mathrm{~d}$ after application, all 5 treatments achieved a boll opening of more than $70 \%$. The highest boll opening rate of $87 \%$ was observed for treatment three; this value was significantly higher than that of the other treatments.

It can be seen from Table 5 that $5 \mathrm{~d}$ after application, only treatment 1 resulted in a positive ripening effect of the cotton; all other treatments exhibited a negative effect. However, it is observed that the ripening effect is slightly lower for treatment 5 than for the control. At $5 \mathrm{~d}$ after application, the ripening effect was limited. The ripening rate of treatment 1 was higher than that of the control group and treatments 2 to 5 did not reach the initial ripening rate of the control group. Therefore, a negative number was obtained for the ripening effect. In addition to the ripening effect, the ripening rate is generally consistent. The results indicate that the ripening effect is optimal for treatment 3 at $15 \mathrm{~d}$ after application. In addition to the ripening effect, the ripening rate is generally consistent. The results indicate that the ripening effect is optimal for treatment 3 at $15 \mathrm{~d}$ after application.

Table 4 Effect of different treatments on the cotton boll opening rate

\begin{tabular}{|c|c|c|c|c|c|c|c|c|c|c|c|}
\hline \multirow{2}{*}{ Treatment } & \multirow{2}{*}{$\begin{array}{l}\text { Total number of } \\
\text { cotton bolls }\end{array}$} & \multirow{2}{*}{$\begin{array}{l}\text { Number of } \\
\text { spit }\end{array}$} & \multirow{2}{*}{$\begin{array}{c}\text { Boll } \\
\text { opening } \\
\text { rate }\end{array}$} & \multicolumn{2}{|c|}{5 days after application } & \multicolumn{2}{|c|}{10 days after application } & \multicolumn{2}{|c|}{15 days after application } & \multicolumn{2}{|c|}{20 days after application } \\
\hline & & & & $\begin{array}{l}\text { Number of } \\
\text { spit }\end{array}$ & $\begin{array}{l}\text { Boll opening } \\
\text { rate }\end{array}$ & $\begin{array}{l}\text { Number of } \\
\text { spit }\end{array}$ & $\begin{array}{l}\text { Boll opening } \\
\text { rate }\end{array}$ & $\begin{array}{l}\text { Number of } \\
\text { spit }\end{array}$ & $\begin{array}{l}\text { Boll opening } \\
\text { rate }\end{array}$ & $\begin{array}{l}\text { Number of } \\
\text { spit }\end{array}$ & $\begin{array}{l}\text { Boll opening } \\
\text { rate }\end{array}$ \\
\hline 1 & 486 & 253 & $52.05 \%$ & 272 & $55.90 \%$ & 300 & $61.70 \%$ & 321 & $66.00 \%$ & 337 & $70.30 \%$ \\
\hline 2 & 549 & 248 & $45.17 \%$ & 278 & $50.60 \%$ & 305 & $55.50 \%$ & 378 & $68.80 \%$ & 442 & $80.50 \%$ \\
\hline 3 & 502 & 243 & $48.40 \%$ & 256 & $50.90 \%$ & 287 & $57.10 \%$ & 373 & $74.30 \%$ & 437 & $87.00 \%$ \\
\hline 4 & 552 & 203 & $36.77 \%$ & 258 & $46.70 \%$ & 305 & $55.20 \%$ & 337 & $61.00 \%$ & 401 & $72.60 \%$ \\
\hline 5 & 557 & 261 & $46.85 \%$ & 284 & $50.90 \%$ & 335 & $60.10 \%$ & 356 & $63.90 \%$ & 398 & $71.40 \%$ \\
\hline CK & 400 & 213 & $53.25 \%$ & 218 & $54.50 \%$ & 223 & $56.00 \%$ & 246 & $61.50 \%$ & 280 & $66.00 \%$ \\
\hline
\end{tabular}

Table 5 Cotton ripening effect for different treatments

\begin{tabular}{ccccc}
\hline Treatment & $\begin{array}{c}\text { Ripening effect } \\
5 \text { days after } \\
\text { application }\end{array}$ & $\begin{array}{c}\text { Ripening effect } \\
\text { 10 days after } \\
\text { application }\end{array}$ & $\begin{array}{c}\text { Ripening effect } \\
\text { 15 days after } \\
\text { application }\end{array}$ & $\begin{array}{c}\text { Ripening effect } \\
\text { 20 days after } \\
\text { application }\end{array}$ \\
\hline 1 & 3.076 & 13.446 & 11.688 & 9.705 \\
2 & -8.571 & -0.564 & 18.961 & 42.647 \\
3 & -7.912 & 3.05 & 33.246 & 61.764 \\
4 & -17.142 & -1.242 & -1.298 & 19.411 \\
5 & -7.912 & 9.83 & 6.233 & 15.882 \\
\hline
\end{tabular}

Table 6 Correlation of defoliation rate between different treatments

\begin{tabular}{ccccc}
\hline Treatment & $\begin{array}{c}\text { 5 days after } \\
\text { application }\end{array}$ & $\begin{array}{c}10 \text { days after } \\
\text { application }\end{array}$ & $\begin{array}{c}15 \text { days after } \\
\text { application }\end{array}$ & $\begin{array}{c}20 \text { days after } \\
\text { application }\end{array}$ \\
\hline 1 & $9.566 \mathrm{~b}$ & $32.533 \mathrm{ab}$ & $63.100 \mathrm{~b}$ & $72.333 \mathrm{a}$ \\
2 & $16.400 \mathrm{~b}$ & $30.466 \mathrm{ab}$ & $63.466 \mathrm{~b}$ & $65.500 \mathrm{~b}$ \\
3 & $17.766 \mathrm{~b}$ & $50.300 \mathrm{~d}$ & $65.066 \mathrm{c}$ & $82.100 \mathrm{~d}$ \\
4 & $16.266 \mathrm{~b}$ & $38.733 \mathrm{bc}$ & $67.166 \mathrm{~b}$ & $81.533 \mathrm{bc}$ \\
5 & $25.266 \mathrm{~b}$ & $43.900 \mathrm{~cd}$ & $68.633 \mathrm{~b}$ & $75.700 \mathrm{bc}$ \\
CK & $8.000 \mathrm{a}$ & $26.133 \mathrm{a}$ & $25.866 \mathrm{a}$ & $36.633 \mathrm{a}$ \\
\hline
\end{tabular}




\section{Advantages of drone spraying over tradtional spraying methods}

\subsection{Working efficiency}

When the plant protection drone flies over the crop, the rotor produces a downward airflow that disturbs the crop leaves, allowing the liquid to penetrate easily and reducing the amount of pesticide by more than $20 \%$; therefore, spraying is more effective. The ideal flight altitude is less than $3 \mathrm{~m}$ and the flight speed is less than $10 \mathrm{~m} / \mathrm{s}$. This greatly improves the work efficiency and it is also more effective for achieving the desired effect of the defoliant. Traditional spraying methods are slow, inefficient, and prone to failure

\subsection{Safety}

Most plant protection drones now carry cameras and can conduct farm inspections during flight operations. This helps farmers better understand crop growth. Therefore, targeted applications of pesticides can be used to control pests or spray pesticides. Moreover, when the drone is flying, the spraying is controlled remotely, which separates the spraying personnel and the pesticide. This is safer and avoids the danger of poisoning by manually applying pesticides.

\subsection{Cost advantage}

The cost of the chemicals used in this trial was as follows: Thiabendron 0.37 yuan $/ \mathrm{g}$, ethephon 0.04 yuan $/ \mathrm{mL}$, additives 0.35 yuan $/ \mathrm{mL}$. The cost per acre for treatments $1-5$ was 17.15 , 17.95, 18.75, 19.55, and 20.35 yuan. The cost of hiring a pilot and drone to spray the cotton defoliating agent is about 10 yuan/acre. In this study, the P30 drone was used; it has a battery capacity to cover five acres. Each battery charge requires $0.8 \mathrm{~kW}$ of electricity, which is $0.16 \mathrm{kWh}$ per acre. At the price of electricity of 0.6 yuan, the electricity fee is 0.096 yuan per acre. The cost of the water used in the experiment is negligible. Moreover, due to the high pesticide concentration and low volume carrying capacity of the drone, the degree of atomization of the liquid is high, which results in a lower cost of the defoliant compared to manual spraying or ground-based mechanical spraying. It takes 5-10 minutes for a drone to operate an acre of land, saving a lot of manpower and time.

\section{Conclusions}

The acceptance of drone operations is not as high in Shandong province as in Xinjiang and many drone operating parameters have not been developed to date. This study was conducted to improve the ripening and defoliation methods used for cotton in Shandong to ultimately improve the cotton grade and the efficiency of machine-based cotton picking. We determined the number of cotton leaves and cotton bolls and the defoliation rate of plants for treatments with different chemical concentrations to determine the optimal dosage. The following conclusions were obtained:

1) The optimum treatment in terms of defoliation and ripening of the cotton in Shandong was treatment 3, i.e., thidiazuron $40 \mathrm{~g}+$ ethephon $90 \mathrm{~mL}+$ fly defense additive $1 \mathrm{~mL}$.

2) During the 20-day test period, the defoliation rate and ripening rate increased most rapidly between $5 \mathrm{~d}$ and $15 \mathrm{~d}$ after the application of the defoliant.

3) The chemical application had a larger effect on the defoliation than the ripening of the cotton and the differences in the defoliation effect were relatively large for the different ethephon concentrations. However, the effect of the ethephon concentrations on the cotton boll ripening rate was not very large.

\section{Acknowledgements}

We acknowledge that this work was financially supported by Top Talents Program for One Case One Discussion of Shandong Province, Development Special Funds on Science and Technology to Guide Local by the Central Government, Program of Shandong Provincial Collaborative Innovation Center of Dry-farming Intelligent Agricultural Equipment Science and Technology Development Program of Zibo and Key R \& D Program of Zibo (2019ZBXC053, 2018kj010073). We also thank the anonymous reviewers for their critical comments and suggestions to improve the manuscript.

\section{[References]}

[1] Wang Guifeng, Wang Qian, Qin Dulin, et al. Investigation report on the development of cotton industry in Shandong province. Cotton Sciences, 2019, 41(04): 3-15. DOI:10.3969/j.issn.2095-3143.2019.04.001.(in Chinese)

[2] Mao Shuchun, Li Yabin, Dong Hezhong. Brilliant 70 Years of China Cotton_ China has embarked on a development path, model and theory of cotton production with Chinese characteristics suitable for national conditions. Cotton Sciences, 2019, 46(07): 1-14. DOI: 10.11963/ 1000-632X.mscmsc.20190715. (in Chinese)

[3] Zhai Xueling, Yuan Ruiling. The change of world cotton industry pattern in the past 30 years and its impact on China's cotton industry. World Agriculture, 2019, (08): 71-78+127-128. DOI: 10.13856/j.cn11-1097/ s.2019.08.009. (in Chinese)

[4] Zhai Xueling. China's Cotton Support Policy Changes and production situation in recent years and its prospect. Agricultural Outlook, 2019, 15(02): 74-77+96. (in Chinese)

[5] Chi Jingze. Study on current situation and countermeasures of cotton planting in Shandong Province. Modern Business Trade Industry, 2017, (32): 5-6. DOI: 10.19311/j.cnki.1672-3198.2017.32.003. (in Chinese)

[6] Wang Jiabao, Gao Mingwei, Zhang Chao, et al. The effect of climate change on cotton breeding in Shandong province. Cotton Sciences, 2018, 45(07): 4-6. DOI: 10.11963/1000-632X.wjbzjs.20180801. (in Chinese)

[7] Zhao Ming, Wang Hongyan, Niu Yujun, et al. Occurrence of cotton boll rot in main cotton producing areas of shandong and analysis of variety resistance. Shandong Agricultural Sciences, 2018, 50(12): 91-95. DOI: 10.14083/j.issn.1001-4942.2018.12.018. (in Chinese)

[8] Zhang F Y,Yuan Y S, et al. Summary of simplified cultivation techniques of cotton in Yellow River basin. Agricultural Science and Technology Newsletter, 2014(12): 196-198. DOI: 10.15889/j.issn.1002-1302.2018.24. 098. (in Chinese)

[9] Cui Aiqin, Han Ruobing, Hu Jilian, et al. The recession and concentration of cotton production in Shandong Province: An analysis framework of comparative advantage. Chinese Journal of Agricultural Resources and Regional Planning, 2019, 40(07): 171-180. DOI: 10.7621/cjarrp.10059121.20190721. (in Chinese)

[10] Jiang Jingchun. Analysis on mechanical picking of cotton in our province. Shangdong Agricultural Mechanization, 2014, (03): 20-21. (in Chinese)

[11] Jia Qingfeng. Exploration of mechanization in the whole process of cotton producti on. Agriculture and Technology, 2019, 39(18): 72-73. DOI: 10.19754/j.nyyjs.2019093 0027. (in Chinese)

[12] Bai Yan, Mao Shuchun, Tian Liwen, et al. Advances and prospects of high-yielding a nd simplified cotton cultivation technology in Xinjiang cotton-growing area. Scientia Agricultura Sinica, 2017, 50(1): 38-50. DOI: 10.3864/j.issn.0578-1752.2017.01.004. (in Chinese)

[13] Bai Y, Mao S X, et al. Advances and prospects of high-yielding and simplified cott on cultivation technology in Xinjiang cotton-growing area. Scientia Agricultur a Sinica, 2017, 50(1): 38-50. (in Chinese)

[14] Qi Wenzhe, Wang Feifei, Meng Zhen, et al. Application status of unmanned aerial vehicle for plant protection in China. Agrochemicals, 2018, 57(04): 247-254. (in Chinese)

[15] Wen Chunjie, Yang Juren, Han Jun, et l. Effect comparison of cotton defoliant spraye $\mathrm{d}$ by plant protection UAV and motor vehicle. Rural Science \& Technology, 2018, (03): 26-27. (in Chinese)

[16] Zhou Yongping, Du Haiying, Shi Shuxin, et al. Effects of planting modes on cotton gr owth,boll and yield under reasonable close-planting. Journal of Inner Mongolia Agricultural University(Natural Science Edition), 2019. DOI: 10.16853/j.cnki.1009 -3575.2019.02.002. (in Chinese) 
[17] Lan Yubin. Current situation and future prospect of precision agriculture aviation technology. Agricultural Engineering Technology, 2017, 37(30): 27-30. DOI: 10.16815 / j.cnki.11-5436/s.2017.30.003. (in Chinese)

[18] Wang Zhe, Feng Hongzu, Wang Lan, et al. Effects comparison of different defoliants applied by Dajiang MG-1S unmanned air vehicle in cotton field. China Cotton, 2018, 45(1): 27-28. DOI: 10.11963/1000632X.wzwl.20180115. (in Chinese)

[19] Zhang Kunpeng, Deng Xijun, Wang Chaoyang. Effects of different composite che micals on cotton ripening and defoliation sprayedby UAV. Agrochemicals, 20 17, 56(8): 619-623. (in Chinese)

[20] Hu Hongyan, Ren Xiangliang, Ma Xiaoyan, et al. Effects of thidiazuron-diuron applie $\mathrm{d}$ by unmanned air vehicle on cotton. China Cotton, 2018, 45(06): 21-23+39. DOI: 10.11963/1000-632X.hhymy. 20180612. (in Chinese)

[21] Wang Yingshan, Xiao Pan. Effect test of cotton defoliant sprayed by UAV. Rural Science \& Technology, 2018(2): 24-25. (in Chinese)
[22] Wang Fangyong, Han Huanyong, Lin Hai, et al. Effects of planting patterns on yield, quality, and defoliation in machine-harvested cotton. Journal of Integrative Agriculture, 2019, 18(9): 2019-2028. DOI: 10.1016/S2095-3119(19)62604-3.

[23] George W. Cathey. Conditioning cotton for increased response to defoliant chemica ls. Field Crops Research, 1985(10): 347-355. DOI: 10.1016/0378-4290(85)90040-1.

[24] Xie Pan. Study on cotton defoliation technology of $80 \%$ thiabenon WP in the rec lamation area of wheat geti. Tarim university, 2019. (in Chinese)

[25] Feng Yizhi, Jin Jie, Pan Jinjun, et al. Residues and degradation dynamics of thidiazur on and diuron in cotton. Modern Agrochemicals, 2017, 16(04): 35-38. DOI: 10.396 9/j.issn.1671-5284.2017.04.011. (in Chinese)

[26] Lv Zhengping, Ji Hanlin. Three clustering validity analysis based on SPSS. Software Guide, 2018, 17(11): 81-85. DOI: 10.11907/ rjdk.182148. (in Chinese) 